\title{
Electronic audit and feedback intervention with action implementation toolbox to improve pain management in intensive care: protocol for a laboratory experiment and cluster randomised trial
}

Wouter T. Gude ${ }^{1 *+}$, Marie-José Roos-Blom ${ }^{1,2+}$, Sabine N. van der Veer ${ }^{3}$, Evert de Jonge ${ }^{2,4}$, Niels Peek ${ }^{3,5}$,

Dave A. Dongelmans ${ }^{2,6}$ and Nicolette F. de Keizer ${ }^{1,2}$

\begin{abstract}
Background: Audit and feedback is often used as a strategy to improve quality of care, however, its effects are variable and often marginal. In order to learn how to design and deliver effective feedback, we need to understand their mechanisms of action. This theory-informed study will investigate how electronic audit and feedback affects improvement intentions (i.e. information-intention gap), and whether an action implementation toolbox with suggested actions and materials helps translating those intentions into action (i.e. intention-behaviour gap). The study will be executed in Dutch intensive care units (ICUs) and will be focused on pain management.

Methods and design: We will conduct a laboratory experiment with individual ICU professionals to assess the impact of feedback on their intentions to improve practice. Next, we will conduct a cluster randomised controlled trial with ICUs allocated to feedback without or feedback with action implementation toolbox group. Participants will not be told explicitly what aspect of the intervention is randomised; they will only be aware that there are two variations of providing feedback. ICUs are eligible for participation if they submit indicator data to the Dutch National Intensive Care Evaluation (NICE) quality registry and agree to allocate a quality improvement team that spends $4 \mathrm{~h}$ per month on the intervention. All participating ICUs will receive access to an online quality dashboard that provides two functionalities: gaining insight into clinical performance on pain management indicators and developing action plans. ICUs with access to the toolbox can develop their action plans guided by a list of potential barriers in the care process, associated suggested actions, and supporting materials to facilitate implementation of the actions. The primary outcome measure for the laboratory experiment is the proportion of improvement intentions set by participants that are consistent with recommendations based on peer comparisons; for the randomised trial it is the proportion of patient shifts during which pain has been adequately managed. We will also conduct a process evaluation to understand how the intervention is implemented and used in clinical practice, and how implementation and use affect the intervention's impact.

(Continued on next page)
\end{abstract}

\footnotetext{
*Correspondence: w.t.gude@amc.uva.nl

${ }^{\dagger}$ Equal contributors

'Department of Medical Informatics, Academic Medical Center, Amsterdam

Public Health research institute, University of Amsterdam, Amsterdam, The

Netherlands

Full list of author information is available at the end of the article
} 
(Continued from previous page)

Discussion: The results of this study will inform care providers and managers in ICU and other clinical settings how to use indicator-based performance feedback in conjunction with an action implementation toolbox to improve quality of care. Within the ICU context, this study will produce concrete and directly applicable knowledge with respect to what is or is not effective for improving pain management, and under which circumstances. The results will further guide future research that aims to understand the mechanisms behind audit and feedback and contribute to identifying the active ingredients of successful interventions.

Trial registration: ClinicalTrials.gov NCT02922101. Registered 26 September 2016.

Keywords: Intensive care, Medical audit, Feedback, Quality improvement, Quality indicators, Randomised controlled trial

\section{Background}

Yearly, approximately 90,000 critically ill patients are admitted to Dutch intensive care units (ICU) [1]. During their time in the ICU many patients are exposed to adverse experiences; acute pain being a leading stressor [2]. Physical and psychological stresses caused by pain have been associated with increased length of stay, morbidity and poor mental health outcomes [3-5], and affect quality of life even after ICU discharge [6,7]. Interview studies revealed that almost half of ICU patients experience moderate to severe pain both at rest as well as during procedures [8-11]. There remains a large gap between ideal and actual care with respect to pain management in intensive care, making it a suitable target for quality improvement (QI) strategies, such as audit and feedback (A\&F) [12-15]. A\&F has been defined as a "summary of clinical performance in a specific area with or without recommendations for action" [16] and aims to support physicians in accurate self-assessment [17].

A Cochrane review of 140 A\&F studies [18] concluded that feedback is effective, but with only a median $4.3 \%$ absolute improvement (interquartile range 0.5 to $16 \%$ ). In fact, a quarter of the studies showed negative or no effect. No effect was also found in a previous $A \& F$ trial undertaken by the National Intensive Care Evaluation (NICE) quality registry in Dutch intensive care units $[19,20]$. A qualitative evaluation explained that physicians experienced several barriers to achieving QI, such as lack of normative standards and benchmarks, inadequate case-mix adjustment, lack of knowledge on how to improve and insufficient allocated time and staff [21]. In attempt to delineate how to most effectively design and deliver A\&F interventions, meta-analyses have indicated that $A \& F$ may be more effective when baseline performance is low, the source is a supervisor or colleague, it is provided more than once, it is delivered in both verbal and written formats, and when it includes correct solution information, explicit targets, and an action plan $[18,22,23]$. However, there is little information to guide operationalisation of these factors [24], limiting the progress with which we learn how to design and deliver effective A\&F interventions [25]. A recent systematic review of electronic A\&F trials alone similarly stressed the scarcity of evidence of effectiveness and the underuse of theory [26]. Researchers have consequently called for theory-informed design and evaluation of A\&F interventions, and two-armed trials of different approaches to providing A\&F to stimulate this progress [27].

\section{Theoretical framework}

Figure 1 depicts our theoretical framework which we based on control theory, specified to reflect the mechanisms through which physicians aim to improve their clinical performance. Control Theory predicts that, if they make a negative assessment of their clinical performance by comparing their performance to a target, physicians develop intentions to take improvement actions and continue these actions until their performance matches the target [28]. However, if they observe discrepancy that is too great, or lack the skills or knowledge on how to improve, recipients may disregard the discrepancy or lower their target to make it more achievable [23, 28, 29].

\section{Studying the information-intention gap in audit and feedback} The key assumption behind the success of A\&F is that it may improve the accuracy with which physicians self-assess [17]. A\&F introduces an external source of information consisting of reports of physicians' own performance and normative data for comparison measured directly from patient records. To that end, A\&F attempts to correct potentially inaccurate perceptions of physicians' own clinical performance and which targets reflect an appropriate performance level. Inaccurate self-assessments may falsely convince physicians that improvement is or is not desirable, resulting in a "misplaced" focus of improvement intentions [30]. However, this key assumption, i.e. whether A\&F yields more accurate self-assessments and adequate improvement intentions, has not been evaluated empirically. This step, to which we will refer as the information-intention gap, is essential in order to initiate behaviour change to improve practice. 


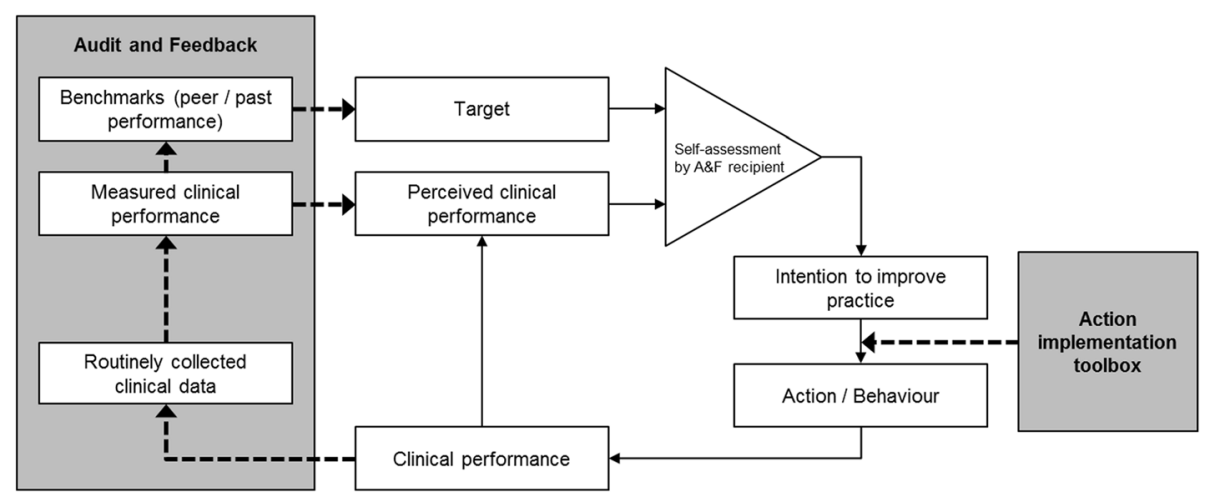

Fig. 1 Illustration of hypothesised role played by A\&F to improve self-assessments of clinical performance and thus improvement intentions, and the action implementation toolbox to promote behaviour change. Adapted from Carver \& Scheier's Control Theory

\section{Closing the intention-behaviour gap in audit and feedback with an action implementation toolbox}

In practice, physicians often do not have the time, capacity or skills to interpret feedback and formulate what improvement action is necessary [21, 31, 32]. Similarly, they can experience barriers preventing them to implement their intended actions [33]. Recognizing that providing feedback information alone may be insufficient for recipients to translate their improvement intentions into behaviour, $A \& F$ interventions have been frequently combined with successful but both intensive and expensive co-interventions, such as educational outreach visits [34]. These co-interventions presumably work because they convince and help participants to take action to improve patient outcomes. Therefore, an intervention aimed to close the intention-behaviour gap could be very effective. In this study, we hypothesise that augmenting A\&F with an action implementation toolbox containing a list of potential barriers in the care process and suggested actions, and supporting materials to facilitate the implementation of actions, helps ICU professionals to turn their intention into action and enhances the likelihood that actions will be completed. Figure 1 illustrates the potential role of the toolbox on effectiveness of A\&F.

\section{Study objectives and hypotheses}

The study has two primary objectives around a newly developed electronic A\&F intervention that aims to improve clinical performance on recently developed quality indicators relating to pain management in Dutch ICUs:

1. To investigate the extent to which A\&F influences physicians' self-assessments of their performance and intentions to improve practice; and
2. To assess the effects of our electronic A\&F intervention with an action implementation toolbox compared to the intervention without toolbox.

We hypothesise that ICUs receiving the A\&F intervention will achieve improvements regardless of whether they have access to the toolbox, but that ICUs using the toolbox will achieve larger and faster improvements than those ICUs that do not. Our secondary objective is to understand how the intervention is implemented and used in clinical practice, and how implementation and use affect the intervention's impact.

\section{Methods}

\section{Study design}

To achieve our objectives, we will perform a mixedmethod study consisting of two parts. In part 1, we will undertake a laboratory experiment among individual ICU professionals to assess the impact of A\&F on their self-assessments and intentions to improve practice (primary objective 1). Although the experiment will not inform the final A\&F intervention design being evaluated in the subsequent field study (i.e. part 2), it might contribute to explaining the A\&F effectiveness observed.

In part 2, we will execute a pragmatic two-armed cluster randomised controlled trial (RCT) to determine the impact of the action implementation toolbox on A\&F effectiveness (primary objective 2). ICU teams in the intervention group will receive online feedback with action planning functionality including access to an integrated toolbox to facilitate planning and implementing actions. The teams in the control group will receive the same intervention but without access to the toolbox; we provided a more detailed description of the intervention below. Cluster randomisation was chosen because the intervention is implemented at the level of ICUs rather 
than individual professionals [35]. The lack of a control group receiving no feedback at all was chosen to avoid attrition (because participants expect something in return for contributing data) and statistical power [36, 37]. The study has been designed and will be reported in accordance with the CONSORT statement [38] and the appropriate extensions [39, 40]. The study is registered with ClinicalTrials.gov (NCT02922101).

\section{Setting}

The setting of our study is Dutch intensive care. In the Netherlands, virtually all ICUs are mixed medical-surgical closed-format units, i.e. units with the intensivist as the patient's primary attending physician. Since 1996 Dutch ICUs can participate in the National Intensive Care Evaluation (NICE) quality registry [1]. Currently, all 32 teaching ICUs (of which 8 university ICUs) and 51 non-teaching ICUs in the Netherlands submit data to the registry and receive biannual written reports on indicating at least the severity of illness in their patient population, standardised mortality ratio, readmission rate and length of stay; each compared to the national average and the average of a group similar sized ICUs. Participants can also view these data, updated after each monthly data upload, on a website called NICE Online and perform subgroup analyses [41]. At the NICE coordination centre, dedicated data managers, software engineers and a coordinator are responsible for routine processing, storing, checking and reporting of these data. The NICE registry uses a framework for data quality assurance [42], including elements like periodical on-site data quality audits and automated data range and consistency checks. To participate in the current study, ICUs must submit an expanded data set needed to calculate the new indicators.

\section{Participants and data collection}

All 83 ICUs that currently submit data to the NICE registry will be invited to participate in our study. They should be willing and able to submit the expanded data set monthly and allocate a QI team consisting of at least one intensivist and one nurse, of which one member is appointed "local champion" who is the key contact person for NICE researchers [43]. Managers and specialist nurses (e.g. a pain management coordinator) are suggested as additional members. The team is asked to spend at least $4 \mathrm{~h}$ per month on the intervention. The medical manager of the ICU must sign a consent form to formalise the organisation's commitment. In the laboratory experiment (part 1), participants are the individual members of the QI teams, whereas in the RCT (part 2) participants are the ICUs.

We will use the existing data collection methods as currently applied by the NICE registry [44]. Data items needed to calculate the new quality indicators are aimed at not increasing registration burden and hence concern items already registered in ICUs' electronic health record or patient data management systems. ICUs upload their data from their local database to the central NICE registry database through secure automatic data extractions.

\section{Intervention}

All participating ICUs will receive access to an online quality dashboard (Fig. 2) that provides two key functionalities: (1) gaining detailed insight into clinical performance on quality indicators; and (2) developing and managing action plans. ICUs in the intervention group of the RCT additionally receive access to an integrated action implementation toolbox designed to further support the development and management of action plans. We designed the quality indicator set, toolbox and dashboard after careful review of the empirical and theoretical evidence in A\&F literature and with continuous involvement by ICU clinicians. Additional file 1 summarises our intervention design by comparing it against Brehaut et al.'s [45] recent list of $15 \mathrm{~A} \& \mathrm{~F}$ design suggestions.

\section{Quality indicators and action implementation toolbox}

Feedback will be provided on four pain management indicators that are listed in Table 1 . We derived this indicator set using a modified RAND method. The method combines literature and guideline review with knowledge from ICU experts in an extensive rating and consensus procedure [46]. To address a potential lack of knowledge on how to improve on quality indicators, which was identified as an important barrier in the previous A\&F study by our research group [21], a particular focus was placed on ensuring the actionability of the indicators during their development.

The action implementation toolbox comprises for each quality indicator (e.g. percentage of patients per shift whose pain is measured) a list of potential barriers in the care process (e.g. staff is unaware of the prevailing guidelines for measuring pain every shift), associated suggestions for actions to solve mentioned barriers (e.g. organise an educational training session), and supporting materials to facilitate implementation of the actions (e.g. a slide show presentation discussing the importance and relevance of measuring pain every shift). The toolbox' complete content will be published elsewhere. The development of the toolbox took place in a parallel process to that of the quality indicators; similarly drawing from literature, guidelines and ICU clinicians' expertise. In short, we used the Systems Engineering Initiative for Patient Safety (SEIPS) model [47] to identify the potential barriers in the care structures and processes that could lead to poor performance on each of the indicators. Next, for each barrier we determined a set of goal-oriented 


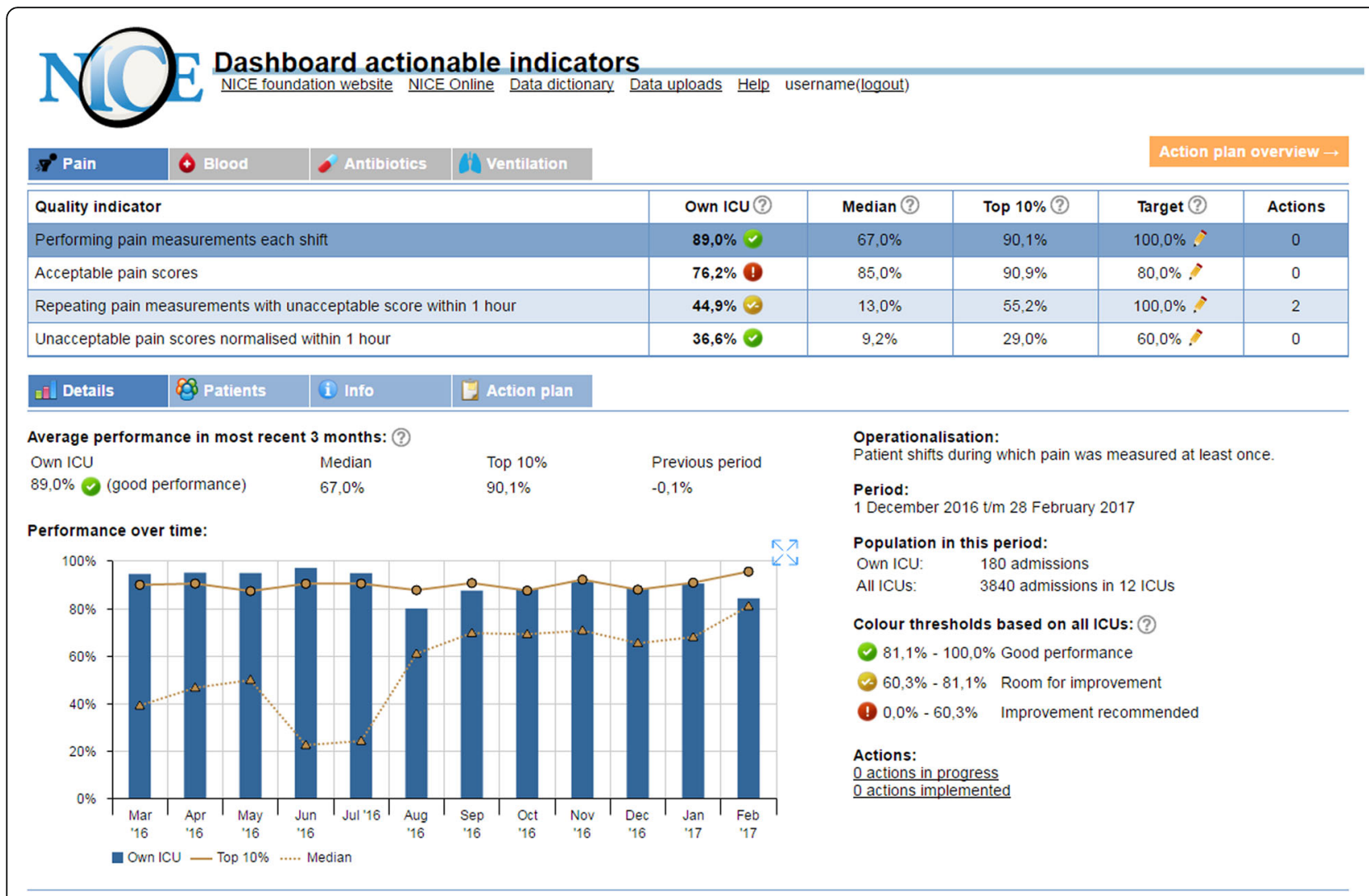

Fig. 2 The NICE dashboard: detailed insight in clinical performance on quality indicators

actions that may improve performance and collected supporting materials that could facilitate the implementation of those actions. The next paragraph explains how the toolbox is integrated in the dashboard.

\section{The NICE dashboard}

To gain insight into clinical performance, the NICE dashboard (Fig. 2) provides an overview of, for each quality indicator, the score achieved by the ICU, the median score of all participating ICUs, the average score achieved by the top $10 \%$ best performing ICUs [48] and a performance assessment represented by a "traffic light" coloured icon; all calculated over the most recent 3 months. Colour-indicated benchmark comparisons have been shown to help health professionals to set improvement intentions that are in line with the A\&F recommendation [49]. Green icons (good performance) are assigned to performance scores above or slightly under the top 10\% benchmark. If not green, yellow icons (room for improvement) are assigned to scores above or

Table 1 Quality indicators used in this study; all fed back as proportions (nominator divided by denominator) with 100\% being the maximum score

\begin{tabular}{|c|c|c|c|c|}
\hline Quality indicator & Type & $\begin{array}{l}\text { Unit of } \\
\text { observation }\end{array}$ & Nominator & Denominator \\
\hline $\begin{array}{l}\text { Performing pain measurements } \\
\text { each shift }\end{array}$ & Process & Patient shift & $\begin{array}{l}\text { Patient shifts during which pain was measured } \\
\text { at least once }\end{array}$ & All patient shifts \\
\hline Acceptable pain scores & Outcome & Patient shift & $\begin{array}{l}\text { Patient shifts during which pain was measured } \\
\text { and no unacceptable pain scores were observed }\end{array}$ & $\begin{array}{l}\text { Patient shifts during which } \\
\text { pain was measured }\end{array}$ \\
\hline $\begin{array}{l}\text { Repeating pain measurements with } \\
\text { unacceptable score within } 1 \mathrm{~h}\end{array}$ & Process & Patient shift & $\begin{array}{l}\text { Patient shifts during which an unacceptable pain } \\
\text { score was measured, and pain was re-measured } \\
\text { within } 1 \mathrm{~h}\end{array}$ & $\begin{array}{l}\text { Patient shifts during which an } \\
\text { unacceptable pain score was } \\
\text { measured }\end{array}$ \\
\hline $\begin{array}{l}\text { Unacceptable pain scores normalised } \\
\text { within } 1 \mathrm{~h}\end{array}$ & Outcome & Patient shift & $\begin{array}{l}\text { Patient shifts during which an unacceptable pain } \\
\text { score was measured, and pain was re-measured } \\
\text { within } 1 \mathrm{~h} \text { indicating that the pain score was } \\
\text { normalised }\end{array}$ & $\begin{array}{l}\text { Patient shifts during which an } \\
\text { unacceptable pain score was } \\
\text { measured }\end{array}$ \\
\hline
\end{tabular}


slightly under the median benchmark; red icons (improvement recommended) are assigned otherwise. The precise thresholds for assigning green or yellow lie $x$ below the corresponding benchmarks, where $x$ is the standard deviation (SD) of performance scores at ICU level with a ceiling limit of benchmark/10. For example, if the top $10 \%$ benchmark is $80 \%$ and the SD of performance scores is $20 \%$, the threshold for assigning a green icon is $80-8 \%=72 \%$. This strategy was chosen to optimise the balance between providing sufficient "green" to prevent feedback rejection and providing enough "yellow" and "red" to encourage participants to undertake action. In particular, ICU clinicians involved in the dashboard design stated that they would consider performance scores that are just below the benchmark still "good performance"; receiving the recommendation to improve practice would seem unfair and could lead to recipients not accepting the feedback. From the dashboard overview, users can drill down to see detailed performance information, using trend charts displaying their own and peer performance over time, performance scores grouped by most relevant patient subgroups (e.g. only surgical patients; only patients during night shifts), and lists of individual patient numbers and whether or not the indicator was violated during a shift. The patient subgroup analyses and lists can be used to further investigate potential barriers in the care process and take corrective action where necessary [50], may increase trust in (quality of) the data [29], and have been previously identified as success factors in A\&F [51]. Additional static information about the indicators are available, namely, their operationalisation, goal, relation to quality, definitions, inclusion and exclusion criteria, type (process or outcome) and unit of observation. Performance information is updated automatically each time an ICU submits new data.

To develop and manage structured action plans, users can navigate to the "action plan" tab. All ICUs can list their potential barriers in the care process and what actions they plan to undertake to improve. For each action, users can assign persons, set a deadline and record additional free-text details. ICUs in the intervention group of the RCT start out with an action plan that is prefilled with the toolbox' list of potential barriers and suggested actions. The suggested actions are indicated by an icon of the NICE registry and include both a short description and detailed description justifying the action's potential supported by relevant literature references. Some actions are accompanied by supporting materials to facilitate their implementation that can be directly downloaded through the dashboard.

\section{Procedure for part 1: laboratory experiment}

The laboratory experiment takes place approximately 1 month before ICU teams receive their first feedback on the new quality indicators (Fig. 3). The experiment consists of two rounds which both take place using an adapted version of the NICE dashboard in which the action plan and toolbox are inaccessible. In the first round, the indicators and their static information (see Intervention) are presented, but measured performance information is withheld. Participants are asked to estimate for each indicator their own ICU's performance score (perceived clinical performance; range 0-100\%) and the average score in Dutch ICUs (perceived peer performance; range $0-100 \%$ ), fill out the minimum performance score they would consider "good" performance (target; range $0-100 \%$ ), and whether or not they would perform actions to improve upon the selected indicator (intention to improve practice; range yes/no). According to Control Theory [28], if participants make a negative self-assessment of their performance (i.e. perceived clinical performance $<$ target) they will develop intentions to improve practice (i.e. intention $=$ yes) and vice versa. If this hypothesis is violated (e.g. negative selfassessment but no intention to improve), participants are asked to explain their choice using a predefined list of reasons (Table 2) or in free text. The provided predefined reasons were developed guided by theoretical behaviour change frameworks $[52,53]$ and previous work $[49,54]$.

In the second round, participants are additionally exposed to all detailed performance information for the indicators including their own performance; the median and top 10\% benchmarks; and past performance levels. Participants are asked the same as in round 1, but this time based on the feedback information at hand, their performance target (range 0-100\%) and intention to improve practice (range yes/no). During this round, if

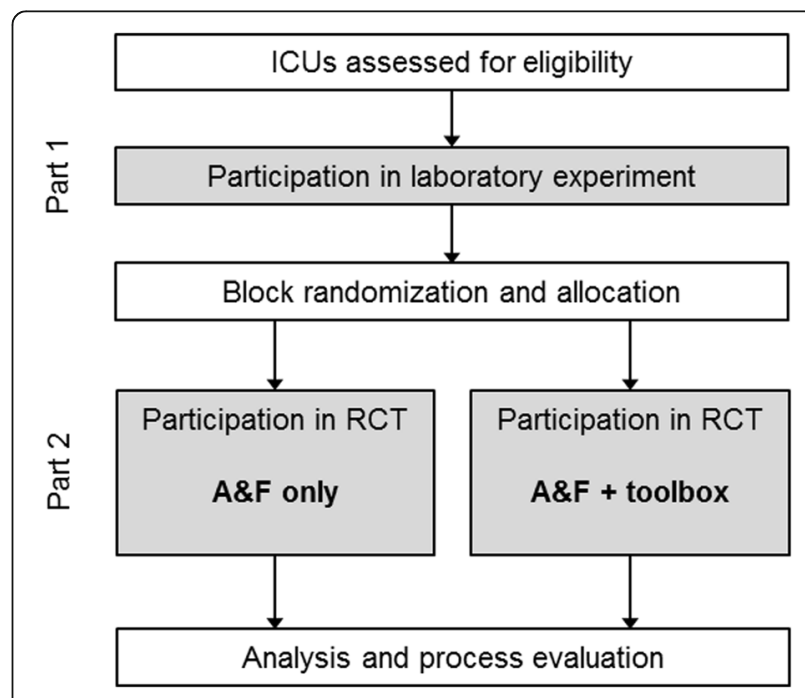

Fig. 3 Study flow. ICU intensive care unit, RCT randomised controlled trial, $A \& F$ audit and feedback 
Table 2 Predefined reasons to be asked if hypotheses posed by Control Theory are violated

\begin{tabular}{ll}
\hline Hypothesis violation & Predefined reason \\
\hline Negative self-assessment but no improvement intention & This indicator is not an important/relevant aspect of intensive care \\
& Actions will not improve our performance score on this indicator \\
& We lack the resources/time/knowledge to take action for this indicator \\
& Me or my colleagues cannot be motivated to take action for this indicator \\
& The benchmark (median/top 10\%) is unrealistic/unfeasible (round 2 only) \\
Positive self-assessment but improvement intention & The measured performance score for our ICU is inaccurate (round 2 only) \\
& This indicator is an essential aspect of quality of intensive care \\
\hline & It is easy to improve our performance score on this indicator \\
\hline
\end{tabular}

improvement intentions do not match with the performance assessment presented in the dashboard (e.g. room for improvement [yellow icon] but no intention to improve), participants are again asked to explain their choice using the same list of predefined reasons as in round 1, extended with three reasons relating to feedback rejection (Table 2) or free text.

Finally, if there are discrepancies between improvement intentions in the first and second round (e.g. initially participants did not develop intention to improve on a specific indicator, but after receiving feedback they did), participants are asked what feedback elements caused this (measured performance score were higher/lower than expected; benchmarks were higher/lower than expected; there was a green/yellow/red icon; other [free text]).

\section{Procedure for part 2: cluster randomised controlled trial}

ICUs enrol in the RCT after completing the laboratory experiment on the pain indicators (Fig. 3). Each ICU will receive one educational outreach visit aimed at explaining the dashboard functionalities, how data should be interpreted and how action plans can be developed. The visits will be undertaken by one of two NICE investigators (MRB or WG) with a non-medical but QI background. Further, brief semi-structured telephone calls will be held monthly with each ICU's contact person to gain progress reports, motivate them to continue using the intervention and provide technical assistance if necessary. The structure of the visits and monthly calls will be the same for all ICUs, with the exception that the action implementation toolbox and its contents will not be mentioned to teams in the control arm. ICUs will participate in the RCT from 6 to 9 months.

\section{Randomisation and allocation}

We will randomly allocate participating ICUs to receive "A\&F only" or "A\&F with action implementation toolbox" in a 1:1 ratio. We will randomise ICUs using a block randomisation, with randomly permuted blocks of two or four each consisting of an equal number of interventions and controls. A researcher, who is otherwise unaffiliated with the study and blinded to the identity of the units, will perform the randomisation according to a computer-generated random schedule produced using an R script (R Foundation for Statistical Computing; Vienna, Austria) before the study starts. The size and the contents of the randomisation blocks will be concealed from the investigators enrolling the ICUs. Participants will not be told explicitly what aspect of the intervention is randomised; they will only be aware that there are two variations of providing $A \& F$. Due to the character of the intervention, it is not possible to blind the investigators.

\section{Outcome measures}

The primary outcome of the laboratory experiment (study part 1) is the proportion of improvement intentions set by participants that are consistent with A\&F recommendations. We consider improvement intentions to be consistent with recommendations when participants intend to improve indicators with room for improvement (i.e. red or yellow) and when they do not intend to improve indicators without room for improvement (i.e. green). This measure was chosen because A\&F should help recipients focus their efforts and allocate their resources on indicators for which improvement is recommended and not on indicators for which it is not. We will compare consistency within participants before and after receiving feedback. We will further report on the difference between perceived clinical performance (before receiving feedback) and measured performance; difference between performance targets set by participants (before receiving feedback) and the benchmarks determined by the A\&F; whether set performance targets after receiving feedback tend to move to the median or top $10 \%$ benchmark; and reasons for not intending to improve on indicators despite a negative selfassessment (i.e. perceived clinical performance $<$ target) and vice versa.

The primary outcome of the RCT (study part 2) is the proportion of patient shifts during which pain has been 
adequately managed, meaning that there was no unacceptable pain and that if there was acceptable pain, this was normalised within $1 \mathrm{~h}$. This proportion reflects the composite performance of an ICU with respect to the individual pain management indicators, as detailed in Table 1. Our unit of observation is a patient shift; defined as a specific ICU patient during a specific shift (i.e. night, morning or day shift). Secondary outcome measures are the performance scores on the individual quality indicators underlying the composite score.

\section{Sample size}

Sample size calculations for the RCT were based on pilot data of pain measurements from six ICUs (five teaching and one non-teaching) in 2014. Based on these data, the mean performance score for pain management is expected to be $76 \%$ with a standard deviation of $0.05 \%$. We assumed a cluster size of 300 patient shifts per ICU per 3 months ( 3 months $\times 10$ average number of patients $\times 10$ average length of stay in shifts). The control arm, receiving only $A \& F$, is expected to increase performance by a median of $4.3 \%$ (absolute improvement) based on the Cochrane review of previous A\&F studies [18]. To have $80 \%$ power to find a difference in performance score for pain management of $10 \%$ using a two-sided unpaired $t$ test with $\alpha=0.05$ would require a total of 24 ICUs to participate in the study.

We did not perform a sample size calculation for the laboratory experiment (study part 1) because this experiment will be conducted in the context of the RCT.

\section{Statistical analysis}

Descriptive statistics will be calculated for all variables of interest. Categorical variables will be summarised using counts and percentages. We will use mixed-effects logistic regression analysis for the main analysis in both parts of the study.

To assess the influence of A\&F on self-assessments and improvement intentions (laboratory experiment in part 1), we will use a binary "A\&F received" covariate. To adjust for correlations between repeated observations within participants we will add a random intercept for "participating professional". To adjust for clustering effects within ICUs and around quality indicators, we will add random intercepts for "ICU" and "quality indicator".

To assess the effect of receiving the action implementation toolbox on pain management performance (RCT in part 2), we will use "patient shift" as unit of analysis. We will include the covariates time, study arm and the interaction term time $\times$ study arm, while adding random effects to adjust for clustering within ICUs, patients and shifts. If we suspect problems with the randomisation, we will perform tests of imbalance between groups in baseline variables that may influence the outcome, i.e. age, gender, length of stay and severity of disease at patient-level and hospital type and ICU-level. In case of an imbalance (above 5\% level for statistical significance), we will conduct a sensitivity analysis adjusted by these variables to test the robustness of our methods [55].

\section{Process evaluation}

We will perform a process evaluation using both quantitative and qualitative methods to gain insight in how the $A \& F$ intervention is implemented and used in clinical practice, and explore if and how implementation and use may affect the intervention's impact [56].

For the quantitative part we will analyse usage logs of the dashboard to investigate the frequency with which the dashboard is used and by whom, and how this varies between ICUs and over time. We will also assess which areas of clinical performance (i.e. which indicators) users tend to focus on, and which feedback components (indicator details, patient subgroup analyses and patient lists) they typically access, and under which circumstances. Finally, we will study the contents of the action plans including the number of planned actions, whether those were typically selected from the action implementation toolbox or selfdefined, and whether and when the actions are implemented. Analysing the usage logs of digital interventions allows us to study the intervention process quantitatively and unobtrusively [57].

For the qualitative part, we will collect data during the monthly telephone calls. Guided by quantitative summary reports drawn from the usage logs, we will investigate participants' experiences with the dashboard, how they have implemented the dashboard into daily clinical practice (e.g. do they organise monthly team meetings to review the feedback; is the manager or intensivist involved; how much time do they invest in QI activities) and ICU- and individual-level barriers and facilitators that may affect the planning and implementation of actions or the intervention's impact.

\section{Discussion}

In order to learn how to design and deliver effective electronic A\&F interventions, we need to understand the mechanisms of how A\&F leads to improvements in clinical performance. Our study uses a theory-informed approach to investigate how A\&F affects improvement intentions among ICU professionals (i.e. information-intention gap), and whether an action implementation toolbox with suggested actions and materials helps translating those intentions into action (i.e. intention-behaviour gap) in a two-armed RCT. The laboratory experiment, RCT and the 
comprehensive process evaluation are expected to provide insightful understanding of the mechanisms behind A\&F.

\section{Strengths and limitations}

The principal strength of our study is the extensive use of Control Theory [28] as a basis for our study objectives, design and evaluation. Although there is growing recognition that theory should play a central role in the design and evaluation of A\&F interventions [27], explicit use of theory remains scarce $[26,58]$. For example, the laboratory experiment (study part 1) will test the hypothesis that A\&F improves self-assessments of clinical performance and hence improvement intentions; this hypothesis is typically assumed to be true in A\&F studies but has not, to the best of our knowledge, been evaluated empirically. Also, while the large majority of quantitative evaluations A\&F interventions solely report effects on clinical performance, our study will also explore the underlying mechanisms of $\mathrm{A} \& \mathrm{~F}$ in an extensive process evaluation. Due to the electronic nature of our A\&F dashboard, we are able to observe essential behavioural constructs such as intentions (planned actions), and behaviour change (completed actions), allowing us to quantify and study their relationships and potentially explain any outcome variation [57]. Further, because we will perform the qualitative part of our process evaluation guided by quantitative process reports, we may be able to make more effective and efficient use of our qualitative method by asking more focused questions.

We based the design of our intervention on theoretical and empirical evidence from A\&F literature and carefully considered what feedback information to provide and how to present it $[18,23,28,30,45,59-62]$. Although this increases the probability that the intervention as a whole will positively affect intensive care performance, we know from four decades of A\&F trials that the effects are variable and often marginal [18]. Therefore, an RCT comparing the intervention to usual care would produce a limited amount of new knowledge [25]. In line with the international research agenda for A\&F studies, our head-to-head comparison of different approaches to A\&F delivery, with versus without action implementation toolbox, will contribute to speeding up the rate with which we identify the active ingredients of successful A\&F interventions [27].

There are some limitations relating to the selection of participants in our study. Eligible ICUs are participating in the NICE registry, are capable of submitting the data items for the quality indicators and agree to allocate a QI team. These criteria may lead to the selection of a nonrepresentative sample of ICUs, because eligible facilities are less likely to be understaffed and more likely to have information technology support to facilitate routine collection of NICE data. Therefore, the generalisability of our findings may be limited to ICUs that are motivated and equipped to systematically monitor and improve the quality of care they deliver. However, as information technology support are rapidly improving in most hospitals, we believe that this will be of less concern in the future. Finally, there is some evidence that non-teaching hospitals use pain assessment tools more often than teaching hospitals [12]. Even though applying a stratification method according to hospital type would equalise the distribution of hospital types over the two arms in the RCT (study part 2) and thus prevent confounding by this variable [63], we expect there will be insufficient participants to do so. Therefore, in case of an imbalance between arms at baseline, we will assess the robustness of our findings by means of a sensitivity analysis.

\section{Potential implications for practice and research}

The results of this study will inform providers and managers in ICU or other clinical settings on how to use indicator-based performance feedback in conjunction with an action implementation toolbox to accelerate systematic local QI. Within the ICU context, this study will produce concrete and directly applicable knowledge with respect to what is or is not effective for improving pain management, and under which circumstances. If the study is successful, the dashboard and action implementation toolbox will be made available to all 83 ICUs in the Netherlands $(100 \%)$ that currently participate in the NICE registry.

The results will also guide future research that aims to understand the mechanisms behind $\mathrm{A} \& \mathrm{~F}$ and identify success factors of effective interventions. For example, if the laboratory experiment in study part 1 shows that ICU professionals' intentions are not or rarely influenced by feedback, an implication is that more effort should be put in closing the information-intention gap before seeking to enhance any subsequent step in the A\&F cycle. Alternatively, its feedback does effectively influence intentions, room for improving $\mathrm{A} \& \mathrm{~F}$ interventions is more likely found in subsequent steps. Second, a positive result from the RCT in study part 2 will suggest that the addition of an action implementation toolbox effectively reduces the intention-behaviour gap. The process evaluation may then reveal how, e.g. because it helps ICU professionals overcome a knowledge, time, capacity or skill barrier to come up with or complete actions. An effective toolbox could take over the role of costly and labour-intensive co-interventions such as educational outreach visits while increasing intervention feasibility. However, a negative result from the RCT will suggest a need for a revision of the toolbox in 
terms of contents or usability, or alternative or more intensive approaches to facilitate ICU professionals to achieve their QI targets.

\section{Future research}

Our research team is currently extending the set of quality indicators and the action implementation toolbox to cover blood transfusions, antibiotic use, and mechanical ventilation (e.g. [64]). ICUs that complete the RCT and submit all data items necessary to calculate the new indicators will all gain access to the toolbox and receive performance feedback on the new indicators in addition to the ones relating to pain management. Our future research will aim at validating our study results by means of an interrupted time series analysis and preceding laboratory experiment using these indicators.

\section{Additional file}

Additional file 1: Summary of our intervention design by comparing it against Brehaut et al.'s [45] recent list of 15 A\&F design suggestions. Note that the term "action" in Brehaut et al.'s table refers to the clinical feedback topic (i.e. indicators) whereas in this study we use "action" to indicate behaviour in response to receiving feedback. (DOCX $18 \mathrm{~kb}$ )

\section{Abbreviations}

A\&F: Audit and feedback; ICU: Intensive care unit; NICE: National Intensive Care Evaluation Foundation; QI: Quality improvement; RCT: Randomised controlled trial; SD: Standard deviation; SEIPS: Systems Engineering Initiative for Patient Safety

\section{Acknowledgements}

The authors would like to acknowledge all clinicians that provided input for the development of the quality indicators and action implementation toolbox. We also thank our software engineers Richard Minne, Eric van der Zwan and Winston Tjon Sjoe Sjoe for their work in developing the NICE dashboard, and Rebecca Holman for her statistical assistance.

\section{Funding}

This study was funded by the National Intensive Care Evaluation (NICE) foundation's own resources.

\section{Availability of data and materials}

Not applicable.

\section{Authors' contributions}

All authors contributed to study conception and participated in critically appraising and revising the intellectual content of the manuscript. WG and MRB were equally and primarily responsible for the manuscript draft. All authors read and approved the final manuscript.

\section{Competing interests}

The authors declare that they have no competing interests.

\section{Consent for publication}

Not applicable.

\section{Ethics approval and consent to participate}

The Institutional Review Board (IRB) of the Academic Medical Center (Amsterdam, The Netherlands) informed us that formal IRB approval and patient consent was not deemed necessary because to the focus of intervention on improving organisational processes; individual patients will not be directly involved (IRB reference number: W16_271). Additionally, in the Netherlands there is no need to obtain consent to use data from registries that do not contain patient-identifying information, as is the case in the NICE registry. The NICE foundation is officially registered according to the Dutch Personal Data Protection Act.

\section{Publisher's Note}

Springer Nature remains neutral with regard to jurisdictional claims in published maps and institutional affiliations.

\section{Author details}

${ }^{1}$ Department of Medical Informatics, Academic Medical Center, Amsterdam Public Health research institute, University of Amsterdam, Amsterdam, The Netherlands. ${ }^{2}$ National Intensive Care Evaluation (NICE) foundation, Amsterdam, The Netherlands. ${ }^{3} \mathrm{MRC}$ Health eResearch Centre, Division of Informatics, Imaging and Data Sciences, Manchester Academic Health Science Centre, The University of Manchester, Manchester, UK. ${ }^{4}$ Department of Intensive Care Medicine, Leiden University Medical Center, Leiden, The Netherlands. ${ }^{5} \mathrm{NIHR}$ Greater Manchester Primary Care Patient Safety Translational Research Centre, Manchester Academic Health Science Centre, The University of Manchester, Manchester, UK. ${ }^{6}$ Department of Intensive Care Medicine, Academic Medical Center, University of Amsterdam, Amsterdam, The Netherlands.

Received: 7 April 2017 Accepted: 4 May 2017

Published online: 25 May 2017

\section{References}

1. van de Klundert N, Holman R, Dongelmans DA, de Keizer NF. Data resource profile: the Dutch National Intensive Care Evaluation (NICE) registry of admissions to adult intensive care units. Int J Epidemiol. 2015;44: 1850-1850h.

2. Rotondi AJ, Chelluri L, Sirio C, Mendelsohn A, Schulz R, Belle S, et al. Patients' recollections of stressful experiences while receiving prolonged mechanical ventilation in an intensive care unit*. Crit Care Med. 2013;30:746-52.

3. Jacobi J, Fraser GL, Coursin DB, Riker RR, Fontaine D, Wittbrodt ET, et al. Clinical practice guidelines for the sustained use of sedatives and analgesics in the critically ill adult. Crit Care Med. 2002;30:119-41.

4. Barr J, Fraser GL, Puntillo K, Ely EW, Gélinas C, Dasta JF, et al. Clinical practice guidelines for the management of pain, agitation, and delirium in adult patients in the intensive care unit. Crit Care Med. 2013;41:263-306.

5. Payen JF, Bosson JL, Chanques G, Mantz J, Labarere J, DOLOREA Investigators. Pain assessment is associated with decreased duration of mechanical ventilation in the intensive care unit: a post Hoc analysis of the DOLOREA study. Anesthesiology. 2009;111:1308-16.

6. Schelling G, Stoll C, Haller M, Briegel J, Manert W, Hummel T, et al. Healthrelated quality of life and posttraumatic stress disorder in survivors of the acute respiratory distress syndrome. Crit Care Med. 1998;26(4):651-9.

7. Jones C, Bäckman C, Capuzzo M, Flaatten H, Rylander C, Griffiths RD. Precipitants of post-traumatic stress disorder following intensive care: a hypothesis generating study of diversity in care. Intensive Care Med. 2007;33:978-85.

8. Carroll KC, Atkins PJ, Herold GR, Mlcek CA, Shively M, Clopton P, et al. Pain assessment and management in critically ill postoperative and trauma patients: a multisite study. Am J Crit Care. 1999;8:105-17.

9. Stanik-Hutt JA, Soeken KL, Belcher AE, Fontaine DK, Gift AG. Pain experiences of traumatically injured patients in a critical care setting. Am J Crit Care. 2001;10:252-9. Available from: http://www.ncbi.nlm.nih.gov/ pubmed/11432213\%5Cnhttp://www.ncbi.nlm.nih.gov/entrez/query. fcgi?cmd=Retrieve\&db=PubMed\&dopt=Citation\&list_uids=11432213.

10. Puntillo KA, Wild LR, Morris AB, Stanik-Hutt J, Thompson CL, White C. Practices and predictors of analgesic interventions for adults undergoing painful procedures. Am J Crit Care. 2002;11:415-31.

11. Chanques MDG, Sebbane MDM, Barbotte MDE, Viel MDPDE, Eledjam MDPDJ-J, Jaber MDPDS. A prospective study of pain at rest: incidence and characteristics of an unrecognized symptom in surgical and trauma versus medical intensive care unit patients. Anesthesiology. 2007;107:858-60.

12. van der Woude MCE, Bormans L, Hofhuis JGM, Spronk PE. Current use of pain scores in dutch intensive care units: a postal survey in the Netherlands. Anesth Analg. 2016;122:456-61. 
13. Tabah A, De Waele J, Lipman J, Zahar JR, Cotta MO, Barton G, et al. The ADMIN-ICU survey: a survey on antimicrobial dosing and monitoring in ICUs. J Antimicrob Chemother. 2015;70:2671-7.

14. Murphy DJ, Pronovost PJ, Lehmann CU, Gurses AP, Whitman GJR, Needham DM, et al. Red blood cell transfusion practices in two surgical intensive care units: a mixed methods assessment of barriers to evidence-based practice. Transfusion. 2014;54:2658-67.

15. Neto AS, Simonis FD, Barbas CS V, Biehl M, Determann RM, Elmer J, et al. Lung-protective ventilation with low tidal volumes and the occurrence of pulmonary complications in patients without acute respiratory distress syndrome: a systematic review and individual patient data analysis. Crit Care Med. 2015;43:2155-63.

16. Oxman AD, Thomson MA, Davis DA, Haynes B. No magic bullets: a systematic review of 102 trials of interventions to improve professional practice. CMAJ. 1995;153:1423-31.

17. Davis DA, Mazmanian PE, Fordis M, Harrison R Van, Thorpe KE, Perrier L. Accuracy of Physician self-assessment compared with observed measures of competence a systematic review. JAMA. 2006;296:1094-102.

18. Ivers $\mathrm{N}$, Jamtvedt G, Flottorp S, Young JM, Odgaard-Jensen J, French SD, et al. Audit and feedback: effects on professional practice and healthcare outcomes. Cochrane database Syst Rev. 2012 [cited 2014 Nov 18];6:CD000259.

19. van der Veer SN, de Vos MLG, van der Voort PHJ, Peek N, Abu-Hanna A, Westert GP, et al. Effect of a multifaceted performance feedback strategy on length of stay compared with benchmark reports alone: a cluster randomized trial in intensive care*. Crit. Care Med. 2013;41:1893-904.

20. de Vos MLG, van der Veer SN, Wouterse B, Graafmans WC, Peek N, de Keizer $N F$, et al. A multifaceted feedback strategy alone does not improve the adherence to organizational guideline-based standards: a cluster randomized trial in intensive care. Implement Sci. 2015;10:95.

21. de Vos Maartje LG, van der Veer SN, Graafmans WC, de Keizer NF, Jager KJ Westert GP, et al. Process evaluation of a tailored multifaceted feedback program to improve the quality of intensive care by using quality indicators. BMJ Qual Saf. 2013 [cited 2015 May 4];22:233-41.

22. Hysong SJ. Meta-analysis: audit and feedback features impact effectiveness on care quality. Med Care. 2009 [cited 2014 Dec 10];47:356-63.

23. Gardner B, Whittington C, McAteer J, Eccles MP, Michie S. Using theory to synthesise evidence from behaviour change interventions: The example of audit and feedback. Soc Sci Med. 2010 [cited 2014 Nov 27];70:1618-25.

24. Foy R, Eccles MP, Jamtvedt G, Young J, Grimshaw JM, Baker R. What do we know about how to do audit and feedback? Pitfalls in applying evidence from a systematic review. BMC Health Serv Res. 2005 [cited 2014 Dec 10];5:50.

25. Ivers NM, Grimshaw JM, Jamtvedt G, Flottorp S, O'Brien MA, French SD, et al. Growing literature, stagnant science? Systematic review, meta-regression and cumulative analysis of audit and feedback interventions in health care. J Gen Intern Med. 2014;29(11):1534-41.

26. Tuti $T$, Nzinga J, Njoroge $M$, Brown B, Peek $N$, English $M$, et al. A systematic review of electronic audit and feedback: intervention effectiveness and use of behaviour change theory. Implement Sci. 2017; 12:61. doi:10.1186/s13012-017-0590-z

27. Ivers NM, Sales A, Colquhoun H, Michie S, Foy R, Francis JJ, et al. No more "business as usual" with audit and feedback interventions: towards an agenda for a reinvigorated intervention. Implement Sci. 2014;9:14.

28. Carver CS, Scheier MF. Control theory: a useful conceptual framework for personality-social, clinical, and health psychology. Psychol Bull. 1982;92:111-35.

29. van der Veer SN, de Keizer NF, Ravelli ACJ, Tenkink S, Jager KJ. Improving quality of care. A systematic review on how medical registries provide information feedback to health care providers. Int. J. Med. Inform. 2010 [cited 2014 Dec 10];79:305-23.

30. Kluger AN, DeNisi A. The effects of feedback interventions on performance: a historical review, a meta-analysis, and a preliminary feedback intervention theory. Psychol Bull. 119(2):254-284.

31. Ivers N, Barnsley J, Upshur R, Tu K, Shah B, Grimshaw J, et al. My approach to this job is. One person at a time: perceived discordance between population-level quality targets and patient-centred care. Can Fam Physician. 2014;60:258-66.

32. Ivers NM, Tu K, Young J, Francis JJ, Barnsley J, Shah BR, et al. Feedback GAP: pragmatic, cluster-randomized trial of goal setting and action plans to increase the effectiveness of audit and feedback interventions in primary care. Implement. Sci. 2013 [cited 2015 May 13];8:142.

33. Gude WT, van Engen-Verheul MM, van der Veer SN, Kemps HMC, Jaspers MWM, de Keizer NF, et al. Effect of a web-based audit and feedback intervention with outreach visits on the clinical performance of multidisciplinary teams: a cluster-randomized trial in cardiac rehabilitation. Implement Sci. 2016;11:160.

34. O'Brien MA, Rogers S, Jamtvedt G, Oxman A, Odgaard-Jensen J, Kristoffersen $D$, et al. Educational outreach visits: effects on professional practice and health care outcomes. Cochrane Database Syst Rev. 2007;(4):CD000409.

35. Ukoumunne OC, Guilliford MC, Chin S, Serne JAC, Burney PGJ, Donner A. Methods in health service research: evaluation of health interventions at area and organisation level. Br Med J. 1999;319:376-9.

36. Dawson L, Zarin DA, Emanuel EJ, Friedman LM, Chaudhari B, Goodman SN. Considering usual medical care in clinical trial design. PLoS Med. 2009;6(9):e1000111.

37. Eysenbach $\mathrm{G}$. The law of attrition. J Med Internet Res. 2005;7(1):e11.

38. Moher D, Hopewell S, Schulz KF, Montori V, Gøtzsche PC, Devereaux PJ, et al. CONSORT 2010 explanation and elaboration: Updated guidelines for reporting parallel group randomised trials. Int J Surg. 2012;10:28-55.

39. Campbell MKM, Elbourne DDR, Altman DGD. CONSORT statement: extension to cluster randomised trials. BMJ. 2004;328:702. Available from: http://www.bmj.com/content/328/7441/702\%5Cnhttp://www.bmj.com/ content/328/7441/702.short.

40. Zwarentein M, Treweek S, Gagnier JJ, Altman DG, Tunis S, Haynes B, et al. Improving the reporting of pragmatic trials: an extension of the CONSORT statement. J Chinese Integr Med. 2009;7:392-7.

41. de Keizer NF, Peute L, van der Zwan E, Jaspers M, de Jonge E. NICE Online; a web-based tool for monitoring performance measures in intensive care. Netherlands J Crit Care. 2011;15:131-6.

42. Arts DGT, de Keizer NF, Scheffer G-J, Formulation M. Defining and improving data quality in medical registries: a literature review, case study, and generic framework. J Am Med Inf. Assoc. 2002;9:600-11.

43. Flodgren $G$, Parmelli E, Doumit G, Gattellari M, O'Brien MA, Grimshaw J, et al. Local opinion leaders: effects on professional practice and health care outcomes. Cochrane database Syst Rev. 2011;CD000125.

44. Arts D, De Keizer N, Scheffer GJ, De Jonge E. Quality of data collected for severity of illness scores in the Dutch National Intensive Care Evaluation (NICE) registry. Intensive Care Med. 2002;28:656-9.

45. Brehaut JC, Colquhoun HL, Eva KW, Carroll K, Sales A, Michie S, et al. Practice feedback interventions: 15 suggestions for optimizing effectiveness. Ann Intern Med. 2016:164:435-41.

46. Fitch K, Bernstein SJ, Aguilar MD, Burnand B, LaCalle JR, Lazaro P, et al. The RAND/UCLA appropriateness method user's manual. Transformation. 2001;109.

47. Carayon P, Schoofs Hundt A, Karsh B-T, Gurses AP, Alvarado CJ, Smith M, et al. Work system design for patient safety: the SEIPS model. Qual Saf Health Care. 2006;15(Suppl 1):i50-8.

48. Kiefe Cl, Allison JJ, Williams OD, Person SD, Weaver MT, Weissman NW. Improving quality improvement using achievable benchmarks for physician feedback: a randomized controlled trial. JAMA. 2001;285:2871-9.

49. Gude WT, van Engen-Verheul MM, van der Veer SN, de Keizer NF, Peek N. How does audit and feedback influence intentions of health professionals to improve practice? A laboratory experiment and field study in cardiac rehabilitation. BMJ Qual Saf. BMJ Publishing Group Ltd; 2017 [cited 2016 Jul 5];26:279-87.

50. Grant AM, Guthrie B, Dreischulte T. Developing a complex intervention to improve prescribing safety in primary care: mixed methods feasibility and optimisation pilot study. BMJ Open. 2014 [cited 2015 Apr 13]:4:e004153.

51. Brown B, Balatsoukas P, Williams R, Sperrin M, Buchan I. Interface design recommendations for computerised clinical audit and feedback: hybrid usability evidence from a research-led system. Int J Med Inform. 2016;94:191-206.

52. Cabana MD, Rand CS, Powe NR, Wu AW, Wilson MH, Abboud PA, et al. Why don't physicians follow clinical practice guidelines? A framework for improvement. JAMA. 1999;282:1458-65.

53. Ajzen I, Netemeyer R, Ryn M Van, Ajzen I. The theory of planned behaviour. Organ Behav Hum Dec. 1991;50:179-211.

54. Gude WT, Van Der Veer SN, Van Engen-Verheul MM, De Keizer NF, Peek N. Inside the black box of audit and feedback: a laboratory study to explore determinants of improvement target selection by healthcare professionals in cardiac rehabilitation. Stud Health Technol Inform. 2015;216:424-428.

55. Roberts C, Torgerson DJ. Baseline imbalance in randomised controlled trials. BMJ. 1999:319:185.

56. Craig P, Dieppe P, Macintyre S, Michie S, Nazareth I, Petticrew M. Developing and evaluating complex interventions: the new Medical Research Council guidance. BMJ. 2008 [cited 2014 Jul 15];337:a1655. 
57. Gude WT, van der Veer SN, de Keizer NF, Coiera E, Peek N. Optimizing digital health informatics interventions through unobtrusive quantitative process evaluations. Stud Health Technol. Inform. 2016;228:594-8.

58. Colquhoun HL, Brehaut JC, Sales A, Ivers N, Grimshaw J, Michie S, et al. A systematic review of the use of theory in randomized controlled trials of audit and feedback. Implement. Sci. 2013;8:66.

59. Landis-Lewis Z, Brehaut JC, Hochheiser H, Douglas GP, Jacobson RS. Computer-supported feedback message tailoring: theory-informed adaptation of clinical audit and feedback for learning and behavior change. Implement Sci. 2015 [cited 2015 May 4];10:12.

60. Hysong SJ, Best RG, Pugh JA. Audit and feedback and clinical practice guideline adherence: making feedback actionable. Implement Sci. 2006; 1:9.

61. Dowding D, Randell R, Gardner P, Fitzpatrick G, Dykes P, Favela J, et al. Dashboards for improving patient care: review of the literature. Int. J. Med. Inform. Elsevier; 2015 [cited 2015 Apr 17]:84:87-100.

62. Locke $\mathrm{E}$ a, Latham GP. Building a practically useful theory of goal setting and task motivation. A 35-year odyssey. Am Psychol. 2002:57:705-17.

63. Ivers NM, Halperin IJ, Barnsley J, Grimshaw JM, Shah BR, Tu K, et al. Allocation techniques for balance at baseline in cluster randomized trials: a methodological review. Trials. 2012;13:120

64. Roos Blom MJ, Dongelmans D, Arbous MS, de Jonge E, de Keizer N. How to assist intensive care units in improving healthcare quality. Development of actionable quality indicators on blood use. Stud Health Technol Inform. 2015;210:429-33.

\section{Submit your next manuscript to BioMed Central and we will help you at every step:}

- We accept pre-submission inquiries

- Our selector tool helps you to find the most relevant journal

- We provide round the clock customer support

- Convenient online submission

- Thorough peer review

- Inclusion in PubMed and all major indexing services

- Maximum visibility for your research

Submit your manuscript at www.biomedcentral.com/submit 